\title{
Risk Factors for Undernutrition in Children under Five Years Old: Evidence from the 2011 Ghana Multiple Indicator Cluster Survey
}

\section{Ronald Welaga Miah1, Paschal Awingura Apanga ${ }^{2 *}$ and Zakia Abdul-Haq ${ }^{3}$}

${ }^{1}$ Asante Akim North District Health Directorate, Ghana Health Service, Ashanti Region, Ghana

${ }^{2}$ Talensi District Hospital, Ghana Health Service, Talensi, Ghana

${ }^{3}$ School of Health and Related Research (ScHARR), University of Sheffield, UK

\begin{abstract}
Background: Undernutrition is a major public health problem affecting the physical and mental development of infants and young children in Ghana. Inadequate dietary intakes and the prevalence of infections have largely been implicated. This study was conducted to assess the risk factors for Undernutrition in Children under-five years old in Ghana.

Methods: This was a secondary data analysis of the 2011 Multiple Indicator Cluster Survey which included anthropometric measurements of children under five years old. Using the modified United Nations Children's Emergency Fund conceptual framework for undernutrition, the variables of interest were extracted and classified into biological and non-biological variables. Bivariate and logistic regression analysis was conducted using SPSS 21 to identify the risk factors for stunting, underweight and wasting.

Results: The survey recruited 7,550 children, $22.7 \%$ were stunted, $13.4 \%$ were underweight and $6.2 \%$ were wasted. Child age, gender, reported size at child birth, breastfeeding status, having diarrhoea or fever in the preceding two weeks, number of children in the household, child health insurance status, household wealth, and ethnicity and religion of household health and region were risk factors for undernutrition. However, only child age and sex were risk factors for all three indicators (stunting, underweight and wasting).

Conclusion: Undernutrition in Ghana is a multi-sectorial problem largely influenced by the social determinants of health and health inequalities. To reduce the prevalence of undernutrition in Ghana, strategies and interventions should be targeted at building the capacity of health staff and strengthening existing systems. This should include intensifying public health messages on child care, integration and collaboration with key stakeholders in addressing socio-economic inequalities of households and communities as well as the regional discrepancies.
\end{abstract}

Keywords: Undernutrition; Risk factors; Wasting; Stunting; Underweight; Ghana

\section{Background}

Undernutrition is a major public health issue in developing countries especially in Sub-Saharan Africa [1]. Globally, it is the leading cause of deaths in children under five years and accounts for about 3.1 million deaths in children under five years old in developing countries $[2,3]$. In addition, it is estimated that 165 million, 101 million and 52 million children younger than five years were stunted, underweight and wasted respectively [4]. All children have the same growth potential for at least up to the age of seven years [5]. However, food insecurity, environmental factors, disease and the burden of poverty can change growth patterns. The causes of undernutrition in children are complex and inter related and have been summarised in Figure 1 of the modified UNICEF conceptual framework of child survival and development by Black et al. [6].

Diet and disease are the immediate predictors of undernutrition in children under five years old. Household food insecurity, inadequate maternal and child care practices, unhealthy household environment and inadequate health services largely determine if a child has adequate dietary intake or is exposed to infections [6]. These factors are further influenced by income and poverty which are key drivers of undernutrition in children. The growing prevalence of parasitic and bacterial infections in developing countries has largely contributed to undernutrition, which also tends to increase the duration and severity of infections [7]. This puts children at a risk of getting caught in the undernutrition-infection cycle [8].
Since undernutrition affects the physical and mental development of children. These disadvantaged children are likely to progress poorly in school, be less productive in adulthood, earn less and provide poor care for their children, resulting in the intergenerational cycle of poverty [9]. It is estimated that low income in developing countries like Ghana further risk losing between 2 and 3\% of their annual Gross Domestic Product (GDP) from child undernutrition [10].

In Ghana, poverty is a major contributor to food insecurity with poorer households being more likely to have poorer food (quality and quantity) intakes [11]. Agriculture is a major contributor to the Ghanaian economy, but production has declined from 7\% in 2009 to $2.6 \%$ in 2012 and this has negatively impacted in terms of food production and availability of food [12]. Undernutrition rates are not evenly distributed in Ghana and children in the three northern regions (Northern, Upper East and Upper West) of Ghana have lower weight related $\mathrm{Z}$ scores and an increased prevalence of acute undernutrition than those in the southern zone (Ashanti, Western, Eastern, Central,

*Corresponding author: Paschal Awingura Apanga, Talensi District Hospital, Ghana Health Service, Talensi, Ghana, Tel: +233249667938; E-mail: awingura@yahoo.com

Received May 24, 2016; Accepted June 02, 2016; Published June 09, 2016

Citation: Miah RW, Apanga PA, Abdul-Haq Z (2016) Risk Factors for Undernutrition in Children under Five Years Old: Evidence from the 2011 Ghana Multiple Indicator Cluster Survey. J AIDS Clin Res 7: 585. doi:10.4172/2155-6113.1000585

Copyright: ( 2016 Miah RW, et al. This is an open-access article distributed unde the terms of the Creative Commons Attribution License, which permits unrestricted use, distribution, and reproduction in any medium, provided the original author and source are credited. 


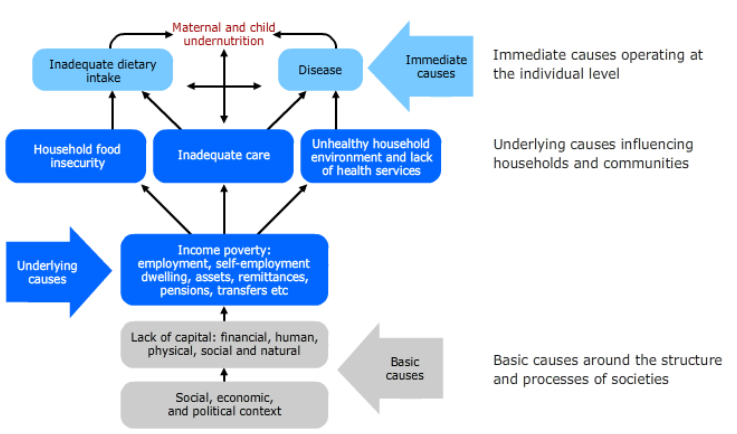

Figure 1: Modified UNICEF conceptual framework for undernutrition.

Volta, Brong-Ahafo and Greater Accra regions) of Ghana [13]. Also, the distribution of rainfall pattern in the country is not even as the three northern regions experience unimodal rainfall whilst the rest of the country has a bimodal rainfall pattern and this negatively affects food security in these regions $[14,15]$.

Urbanisation and the increase in population growth rates has led to an urban population growth increasing from $44 \%$ in 2000 to $50 \%$ in 2010 in Ghana [16]. Rapid urbanisation has resulted in the development of slums, poor housing and inadequate water supply [17]. This has had negative consequences on the wellbeing of the Ghanaian population. Also, the majority of rural households in Ghana do not have potable drinking water $(31 \%)$ compared with those in urban areas where about $91 \%$ of the population have access. About $23 \%$ of the households in rural communities do not have access to any toilet facilities and $38.5 \%$ of children in these areas are considered vulnerable to diarrhoea and other infections [15].

The Government of Ghana has made efforts toward addressing undernutrition in children. It has been a signatory to many international declarations to improve child health and development. Nutrition intervention policies and programs have included food demonstration and nutrition education (1957-1966), attitude/ behaviour change communication in nutrition (1966-1974), weaning foods and supplementary feeding programs (1974-1987), micronutrient deficiencies (1987-1990), exclusive breastfeeding programs (19902000), community based growth monitoring and promotion (20002008) and currently the Scaling Up Nutrition (SUN-2010) program . However, because most of these programs are donor driven, successive governments have not made commitments in terms of allocating sufficient human and financial resources for effective coordination and monitoring and evaluation of these programs, which has affected sustainability [18].

This study was conducted to provide an in-depth analysis of the 2011 Multiple Indicator Cluster Survey data to assess the risk factors of undernutrition in children under five years old. To the best of our knowledge no such analysis has been conducted and we believe that providing evidence of risk factors of undernutrition will help inform policy and decision making regarding resource allocation and nutrition programme interventions in the country.

\section{Methods}

\section{Study design and study area}

This is a secondary data analysis of the 2011 national Multiple Indicator Cluster Survey (MICS) conducted by the Ghana Statistical
Service (GSS), that collected data on the health status of husbands or household heads (15-49 years), and women (15-49 years) with a child under five years old. Full details of the survey are available in the MICS report [15].

Ghana was stratified into ten administrative regions and then into rural and urban. The MICS was a two-stage sample survey. The primary sampling units were randomly selected from the 2010 Ghana population and housing census which was made up of 810 Enumeration Areas (EAs) [19]. Fifteen (15) households were randomly selected in each EA giving a total of 12,150 households of which 11,925 households with 7,550 children under five years old were surveyed. The selection was done using systematic random selection procedures.

\section{Data collection and analysis}

Data were collected by 20 trained field teams that spread across the country using face-to-face questionnaires between SeptemberDecember, 2011. The questionnaires collected information on household, demographic and socio-economic characteristic. Nutrition related data included breastfeeding status, height and weight of children and demographic characteristics.

Clean data files were obtained from the GSS. Frequencies were run to observe distribution patterns and checks made for outliers. The unique identification variables in the household were; father, mother and child files were merged to create a common file. Analysis was carried out using SPSS version 21. Nutritional status is a reflection of health and measured using indices of height for age (HAZ), weight for age (WAZ) and weight for height (WHZ) based on Z-scores. Stunting, underweight and wasting were defined as HAZ, WAZ and WHZ below minus two standard deviations $(<-2$ SD) [20]. These three are therefore the main indicators for undernutrition. Stunting reflects linear growth retardation and it's a measure of chronic undernutrition, wasting reflects acute undernutrition while underweight is a composite measure of both chronic and acute undernutrition.

The MICS used a household wealth index which was based on principal component analysis using household ownership assets such as electricity, television and DVD player, radio, laptop/desktop computers, mobile phone, refrigerator, washing machine, sewing machine, material for floor and roofing, water access and sanitation facilities. Economic inequality was measured by categorising the wealth into five quintiles with the lowest quintile being the proportion of $20 \%$ of the poorest household and the highest quintile representing $20 \%$ of the richest households in Ghana. The variables collected for education of mother and father refer to the highest level of school completed.

Bivariate analysis was conducted using chi squared tests to identify those biological and non-biological factors associated with stunting, underweight and wasting. The variables associated with undernutrition were then used to develop logistic regression models to identify the risk factors for stunting, underweight and wasting. For each of the nutritional indicator, a model was developed for the non-biological factors, i.e., socio-economic and demographic factors, and another for biological factors such as child age, gender, recent morbidity history. The final model used the variables identified as being significant in the above two models. Results of the multivariate analysis are presented as odd ratios. All tests were done using a $95 \%$ confidence interval with a probability value $<0.05$ being considered statistically significant. 


\section{Ethics}

Ethical approval was given by Faculty of Medicine Ethics Committee of the University of Southampton, UK. Approval was also given by the GSS for the use of the 2011 MICS data. This was a secondary analysis of anonymous human data where no individual could be identified from the data set.

\section{Results}

\section{Descriptive analysis}

Table 1 shows a total of 7,550 children under five years old who were included in the study as well as the characteristics of the study population. Study characteristics such as; age of child, sex of child, reported size of child at birth, currently breastfed, diarrhoea in the last 2 weeks, cough in the last 2 weeks, etc. were reported in the study.

\section{Measurement models}

Table 2 is the bivariate analysis model that shows biological and non-biological factors, and their association with stunting, underweight and wasting. The study observed that $22.7 \%$ of the children under five years old were stunted, $13.4 \%$ were underweight and $6.2 \%$ were wasted. For the biological factors, the age of a child was statistically associated with undernutrition (All $\mathrm{p}=0.001$ ). Fewer children under twelve months old were stunted compared with those in the other age groups but the opposite was true for wasting whilst fewer children less than six months were underweight compared with the rest. Also, the sex of child was associated with undernutrition with more boys being stunted, underweight and wasted than girls (All $\mathrm{p}=0.001$ ). The reported size of a child at birth was inversely associated with stunting and underweight (both $\mathrm{p}=0.001)$ but not associated with wasting $(\mathrm{p}=0.219)$.

Whether a child was currently breastfed was associated with undernutrition. More children who were currently breastfed were underweight $(\mathrm{p}=0.008)$ and wasted $(\mathrm{p}=0.001)$ but the opposite was observed for stunting $(\mathrm{p}=0.001)$. Having diarrhoea in the preceding two weeks was positively associated with being stunted $(\mathrm{p}=0.001)$, underweight $(\mathrm{p}=0.001)$ and wasting $(\mathrm{p}=0.046)$. Similarly, children who had a cough in the preceding two weeks were associated with being underweight $(\mathrm{p}=0.003)$ and children who had fever in the preceding two weeks were positively associated with being underweight and wasted (both $\mathrm{p}=0.001$ ).

Among the non-biological factors, location and region of residence were associated with undernutrition. More children in rural areas were associated with stunting $(\mathrm{p}=0.001)$ and underweight $(\mathrm{p}=0.001)$ than those in the urban areas. The region of residence was associated with stunting, underweight and wasting (All $\mathrm{p}=0.001$ ). The prevalence of stunting and underweight were higher in the Northern and Upper East regions while the opposite was true for the Greater Accra region. The Upper West and Volta regions were highly associated with wasting. Increasing household wealth was positively associated undernutrition (All $\mathrm{p}=0.001$ ). Similarly, whether a child had health insurance was associated with better nutrition $(\mathrm{p}<0.05)$.

Both mother's and father's age were associated with stunting $(\mathrm{p}=0.001)$ and underweight $(\mathrm{p}=0.035)$ and maternal age was also associated with wasting $(\mathrm{p}=0.046)$. The pattern was ' $\mathrm{U}$ ' shaped with more children of younger or older parents being undernourished than those in the middle age groups. Additionally, maternal literacy was associated with stunting and underweight (both $\mathrm{p}=0.001$ ) but not wasting $(\mathrm{p}=0.086))$. More children whose mothers could not read at all were associated with stunted and underweight compared with those who could read part or all of a sentence. Unsurprisingly, increasing level of mother's education was also positively associated with a lower prevalence of stunting, underweight and wasting (All $\mathrm{p}=0.001$ ). Father's educational level was associated with stunting and underweight (both $\mathrm{p}=0.001)$ but not wasting $(\mathrm{p}=0.480)$.

Marital status was also associated with stunting $(\mathrm{p}=0.012)$ and underweight $(\mathrm{p}=0.001)$ with fewer children whose mothers were currently or never married being stunted and underweight compared with children of mothers who were formerly married. Whether the husband had other wives was positively associated with stunting and underweight (both $\mathrm{p}=0.001$ ). In addition, the number of children living at home was associated with stunting, underweight and wasting (All $\mathrm{p}=0.001$ ) with greater children from households having five or six being stunted and wasted while the opposite was for underweight. Ethnicity was associated with undernutrition with more children from the Guan and Grusi headed household being stunted $(\mathrm{p}=0.001)$ and underweight $(\mathrm{p}=0.001)$. The prevalence of wasting was highest among the Mole/ Dagbani and Grusi. Grusi were particularly vulnerable to stunting, underweight and wasting. The religion of the household head was also associated with stunting and underweight (both $\mathrm{p}=0.001$ ) but not wasting $(\mathrm{p}=0.298)$. More children from the spiritualist/traditionalist households were stunted and underweight than those from other religions.

Table 3 shows a logistic regression analysis model. Only factors that were significant in the bivariate analysis model were included in the logistic regression model. Among the biological factors, there was an overall effect of age on stunting. Stunting increased with age and peaked at age group 24-35 months, where children were 6.1 times (95\% CI 4.29-8.72) more likely to be stunted than their peers in age group 0-5 months. Also, the risk of underweight increased with a child's age and peaked at 24-35 months old ( $\mathrm{OR}=4.51$ 95\% CI 2.55-7.99). However, children within age groups, 36-47 months (OR=0.42, 95\% CI $0.25-0.68)$ and $48-59$ months old (OR=0.50, 95\% CI 0.30-0.82) were protected against wasting as compared to children within the age group $0-5$ months old. Similarly, females were $26 \%, 38 \%$ and $29 \%$ less likely to be stunted $(\mathrm{OR}=0.74,95 \% \mathrm{CI} 0.64-0.87)$, wasted $(\mathrm{OR}=0.62,95 \% \mathrm{CI}$ $0.51-0.75)$ and underweight $(\mathrm{OR}=0.71,95 \% \mathrm{CI} 0.60-0.84)$ respectively than their male counterparts. The reported size at birth was also a risk factor for stunting and underweight with risk increasing with decreasing reported size at birth.

Breastfeeding status was a risk factor for being underweight and wasted with children who were not breastfed being $61 \%(\mathrm{OR}=0.39$ 95\% CI 0.3-0.89) less likely to be underweight and 43\% (OR 0.57, 95\% CI 0.40-0.80) less likely to be wasted than those who were breastfed. Children who had no diarrhoea in the preceding two weeks were $27 \%$ (OR=0.73 95\% CI 0.59-0.90) less likely to be underweight than those who had diarrhoea. Similarly, children who did not have fever in the preceding two weeks were $27 \%$ (OR=0.73 95\% CI 0.59-0.89) less likely to be wasted than those who had fever.

Among the non-biological factors, region of residence was a risk factor for underweight. Children in the Northern and Upper East regions were 2.02 (95\% CI 1.32-3.11) and 1.65 (95\% CI 1.02-2.66) times more likely to be underweight than those in the Western region. Children from Brong Ahafo region were 58\% (OR=0.42, 95\% CI 0.210.83 ) less likely to be wasted than their colleagues in Western region. However, there was no significant association between Western region and other regions regarding stunting. Being in the richest quintile was protective against stunting $(\mathrm{OR}=0.42,95 \% \mathrm{CI} 0.28-0.63)$ as well as protective against underweight $(\mathrm{OR}=0.4095 \% \mathrm{CI} 0.23-0.70)$ when 
Citation: Miah RW, Apanga PA, Abdul-Haq Z (2016) Risk Factors for Undernutrition in Children under Five Years Old: Evidence from the 2011 Ghana Multiple Indicator Cluster Survey. J AIDS Clin Res 7: 585. doi:10.4172/2155-6113.1000585

Page 4 of 10

\begin{tabular}{|c|c|c|c|}
\hline Variables & Label & No. & $\%$ \\
\hline \multirow{7}{*}{ Age of child (months) } & $0-5$ & 818 & 10.8 \\
\hline & $6-11$ & 725 & 9.6 \\
\hline & $12-24$ & 1453 & 19.2 \\
\hline & $24-35$ & 1553 & 20.6 \\
\hline & $36-47$ & 1576 & 20.9 \\
\hline & $48-59$ & 1426 & 18.9 \\
\hline & Total & 7550 & 100.0 \\
\hline \multirow{3}{*}{ Sex of child } & Male & 3757 & 49.8 \\
\hline & Female & 3793 & 50.2 \\
\hline & Total & 7550 & 100.0 \\
\hline \multirow{6}{*}{ Reported size of child at birth } & Very large & 644 & 8.5 \\
\hline & Larger than average & 1308 & 17.3 \\
\hline & Average & 1821 & 24.1 \\
\hline & Smaller than average & 384 & 5.1 \\
\hline & Very small & 134 & 1.8 \\
\hline & Total & 4292 & 58.8 \\
\hline Variable & Label & No. & $\%$ \\
\hline Currently breastfed & Yes & 2712 & 36.4 \\
\hline \multirow[b]{2}{*}{ Currently breastfed } & No & 4747 & 62.9 \\
\hline & Total & 7459 & 98.8 \\
\hline Diarrhoea in last 2 weeks & Yes & 956 & 12.7 \\
\hline \multirow[b]{2}{*}{ Diarrhoea in last 2 weeks } & No & 6592 & 87.3 \\
\hline & Total & 758 & 100.0 \\
\hline Cough in last 2 weeks & Yes & 1570 & 20.8 \\
\hline \multirow[b]{2}{*}{ Cough in last 2 weeks } & No & 5979 & 79.2 \\
\hline & Total & 7549 & 100.0 \\
\hline Fever in last 2 weeks & Yes & 1427 & 18.9 \\
\hline \multirow{3}{*}{$\begin{array}{c}\text { Fever in last } 2 \text { weeks } \\
\text { Location }\end{array}$} & No & 6122 & 81.1 \\
\hline & Total & 7549 & 100.0 \\
\hline & Urban & 3283 & 43.5 \\
\hline \multirow{2}{*}{ Location } & Rural & 4267 & 56.5 \\
\hline & Total & 7550 & 100. \\
\hline Region & Western & 758 & 10.0 \\
\hline \multirow{10}{*}{ Region } & Central & 740 & 9.8 \\
\hline & Greater Accra & 1142 & 15.1 \\
\hline & Volta & 601 & 8.0 \\
\hline & Eastern & 827 & 11.0 \\
\hline & Asante & 1411 & 18.7 \\
\hline & Brong Ahafo & 671 & 8.9 \\
\hline & Northern & 852 & 11.3 \\
\hline & Upper East & 325 & 4.3 \\
\hline & Upper West & 223 & 3.0 \\
\hline & Total & 7550 & 10.0 \\
\hline Household wealth quintile & Poorest & 1730 & 22.9 \\
\hline
\end{tabular}

\begin{tabular}{|c|c|c|c|}
\hline \multirow{5}{*}{ Household wealth quintile } & Second & 1551 & 20.5 \\
\hline & Third & 1559 & 20.6 \\
\hline & Fourth & 1397 & 18.5 \\
\hline & Richest & 1313 & 17.4 \\
\hline & Total & 7550 & 100.0 \\
\hline Child has health insurance & Yes & 4059 & 53.8 \\
\hline \multirow{2}{*}{ Child has health insurance } & No & 3491 & 46.2 \\
\hline & Total & 7550 & 100.0 \\
\hline Mother's age & $15-19$ years & 232 & 2.1 \\
\hline \multirow{7}{*}{ Mother's age } & 20-24 years & 1058 & 14.0 \\
\hline & $25-29$ years & 1738 & 23.0 \\
\hline & 30-34 years & 1820 & 24.1 \\
\hline & $35-39$ years & 1263 & 16.7 \\
\hline & $40-44$ years & 611 & 8.1 \\
\hline & $45-49$ years & 328 & 4.3 \\
\hline & Total & 7050 & 93.4 \\
\hline Father's age & $<25$ years & 164 & 2.2 \\
\hline \multirow{8}{*}{ Father's age } & $25-29$ years & 792 & 10.5 \\
\hline & $30-34$ years & 1309 & 17.3 \\
\hline & $35-39$ years & 1358 & 18.0 \\
\hline & 40-44y ears & 1043 & 13.8 \\
\hline & $45-49$ years & 706 & 9.4 \\
\hline & $50-54$ years & 368 & 4.9 \\
\hline & $55+$ years & 410 & 5.4 \\
\hline & Total & 6151 & 81.5 \\
\hline Variable & Label & No. & $\%$ \\
\hline Mother's literacy & Cannot read at all & 4610 & 61.1 \\
\hline $\begin{array}{l}\text { Mother's literacy } \\
\text { Mother's education }\end{array}$ & Only parts of a sentence & 575 & 7.6 \\
\hline \multirow{4}{*}{$\begin{array}{l}\text { Mother's literacy } \\
\text { Mother's education } \\
\text { Mother's education }\end{array}$} & Whole sentences & 1019 & 13.5 \\
\hline & Total & 6203 & 82.2 \\
\hline & None & 2954 & 39.1 \\
\hline & Primary & 1628 & 21.6 \\
\hline \multirow{4}{*}{$\begin{array}{l}\text { Mother's education } \\
\text { Father's education }\end{array}$} & Middle/JSS & 2578 & 34.1 \\
\hline & Secondary+ & 390 & 5.2 \\
\hline & Total & 7550 & 100. \\
\hline & None & 1964 & 26.0 \\
\hline Father's education & Primary & 770 & 10.2 \\
\hline \multirow{4}{*}{$\begin{array}{l}\text { Father's education } \\
\text { Marital status }\end{array}$} & Middle/JSS & 2071 & 27.4 \\
\hline & Secondary+ & 579 & 7.7 \\
\hline & Total & 5385 & 71.3 \\
\hline & Currently married & 6372 & 84.4 \\
\hline Marital status & Formerly married & 341 & 4.5 \\
\hline \multirow{4}{*}{$\begin{array}{c}\text { Marital status } \\
\text { Husband has other wives }\end{array}$} & Never married & 337 & 4.5 \\
\hline & Total & 7550 & 93.4 \\
\hline & & & \\
\hline & Yes & 1201 & 15.9 \\
\hline Husband has other wives & No & 5171 & 68.5 \\
\hline
\end{tabular}




\begin{tabular}{|c|c|c|c|}
\hline \multirow{3}{*}{$\begin{array}{l}\text { Husband has other wives } \\
\text { Ethnicity of household head }\end{array}$} & Total & 6372 & 84.4 \\
\hline & & & \\
\hline & Akan & 3122 & 41.3 \\
\hline Ethnicity of household head & Ga/Dangbe & 618 & 8.2 \\
\hline \multirow{7}{*}{$\begin{array}{l}\text { Ethnicity of household head } \\
\text { Religion of household head }\end{array}$} & Ewe & 1008 & 13.4 \\
\hline & Guan & 726 & 9.6 \\
\hline & Mole Dagbani & 1452 & 19.2 \\
\hline & Grusi & 297 & 3.9 \\
\hline & Others & 327 & 4.3 \\
\hline & Total & 7550 & 100.0 \\
\hline & Christian & 4910 & 65.0 \\
\hline Religion of household head & Muslim & 1495 & 19.8 \\
\hline \multirow{4}{*}{$\begin{array}{l}\text { Religion of household head } \\
\text { No. of children living at home }\end{array}$} & Spiritualist/Traditionalist & 574 & 7.6 \\
\hline & Other/None & 571 & 7.6 \\
\hline & Total & 7550 & 100.0 \\
\hline & 1 child & 1529 & 20.2 \\
\hline No. of children living at home & 2 children & 1809 & 24.0 \\
\hline \multirow{5}{*}{ No. of children living at home } & 3 children & 1425 & 18.9 \\
\hline & 4 children & 1148 & 15.2 \\
\hline & 5 children & 664 & 8.8 \\
\hline & $6+$ children & 429 & 5.7 \\
\hline & Total & 7003 & 92.8 \\
\hline
\end{tabular}

Table 1: Distribution of the biological and non-biological characteristics of respondents $(n=7,550)$. compared to the poorest quintile. In addition, a child registered on health insurance had an increasing risk of being underweight $(\mathrm{OR}=1.56$ 95\% CI 1.30-1.87) than children without health insurance. Muslims and traditional headed households were $42 \%$ (OR=1.42, 95\% CI 1.14 $1.77)$ and $46 \%(\mathrm{OR}=1.46,95 \%$ CI $1.15-1.85)$ more likely to be stunted than those from the Christian headed households.

\section{Discussion}

The findings of this study confirm that undernutrition in children less than five years old in Ghana is related to health and sanitation services, economic and regional differences which agree with previous findings [21]. The age of a child was a risk factor for both chronic and acute undernutrition. Stunting was higher in older children which is consistent with studies by Kabubo-Mariara et al. [22] and this may be due to micro and macro nutrient deficiencies, inadequate feeding practices, infections and exposure to pathogens in the environment [23]. Younger children 0-5 months old were less stunted and this may be because they are still being breastfed [24]. Fewer children aged 36-47 months and 48-59 months old were wasted compared with the younger age groups and this might have been due to recent food shortage or seasonal infections [23].

Gender was also found in this study to be a risk factor for both chronic and acute undernutrition. Males were more undernourished than females in this study, which is consistent with studies reported by Van de Poel et al. [25] and Wamani et al. [26]. Zere and Mclntyre [27] have shown that females are advantageous in terms of anthropometry

\begin{tabular}{|c|c|c|c|c|c|c|c|c|c|c|}
\hline \multirow[b]{2}{*}{ Variable } & \multirow[b]{2}{*}{ Label } & \multicolumn{3}{|c|}{ Stunting a } & \multicolumn{3}{|c|}{ Underweight $^{\mathrm{b}}$} & \multicolumn{3}{|c|}{ Wasting $^{c}$} \\
\hline & & No. & $\%$ & p & No. & $\%$ & $\mathbf{p}$ & No. & $\%$ & $p$ \\
\hline \multirow[t]{7}{*}{ Age of child (months) } & $0-5$ & 795 & 7.8 & 0.001 & 801 & 6.7 & 0.001 & 795 & 11.4 & 0.001 \\
\hline & $6-11$ & 714 & 12.5 & & 715 & 15.8 & & 714 & 11.2 & \\
\hline & $12-24$ & 1411 & 26.4 & & 1422 & 16.5 & & 1418 & 7.7 & \\
\hline & $24-35$ & 1516 & 28.2 & & 1519 & 13.5 & & 1520 & 4.7 & \\
\hline & $36-47$ & 1522 & 27.9 & & 1534 & 13.7 & & 1531 & 2.8 & \\
\hline & $48-59$ & 1382 & 21.3 & & 1384 & 12.2 & & 1403 & 4.6 & \\
\hline & Total & 7340 & 22.7 & & 7375 & 13.4 & & 7381 & 6.2 & \\
\hline \multirow[t]{3}{*}{ Sex of child } & Male & 3635 & 25.3 & 0.001 & 3665 & 15.4 & 0.001 & 3665 & 7.3 & 0.001 \\
\hline & Female & 3703 & 20.3 & & 3709 & 11.3 & & 3716 & 5.2 & \\
\hline & Total & 7338 & 22.7 & & 7374 & 13.4 & & 7381 & 6.2 & \\
\hline \multirow{6}{*}{$\begin{array}{l}\text { Reported size of child at } \\
\text { birth }\end{array}$} & Very large & 630 & 15.2 & 0.001 & 632 & 8.9 & 0.001 & 625 & 6.6 & 0.219 \\
\hline & Larger than average & 1280 & 19.9 & & 1286 & 9.2 & & 1287 & 7.5 & \\
\hline & Average & 1774 & 22.7 & & 1789 & 16.5 & & 1782 & 8.9 & \\
\hline & Smaller than average & 378 & 25.7 & & 378 & 19.0 & & 378 & 6.9 & \\
\hline & Very small & 132 & 32.6 & & 129 & 27.1 & & 129 & 10.1 & \\
\hline & Total & 4194 & 21.3 & & 4214 & 13.7 & & 4201 & 8.0 & \\
\hline \multirow[t]{3}{*}{ Currently breastfed } & Yes & 2658 & 17.8 & 0.001 & 2672 & 14.9 & 0.008 & 2658 & 9.9 & 0.001 \\
\hline & No & 4595 & 25.6 & & 4616 & 12.7 & & 4634 & 4.2 & \\
\hline & Total & 7253 & 22.7 & & 7288 & 13.5 & & 7292 & 6.3 & \\
\hline \multirow[t]{3}{*}{ Diarrhoea in last 2 weeks } & Yes & 939 & 29.9 & 0.001 & 942 & 19.2 & 0.001 & 936 & 7.7 & 0.046 \\
\hline & No & 6400 & 21.7 & & 6433 & 12.5 & & 6444 & 6.0 & \\
\hline & Total & 7339 & 22.8 & & 7375 & 13.4 & & 7380 & 6.2 & \\
\hline \multirow[t]{3}{*}{ Cough in last 2 weeks } & Yes & 1542 & 24.3 & 0.112 & 1544 & 15.6 & 0.003 & 1549 & 7.0 & 0.134 \\
\hline & No & 5796 & 22.3 & & 5831 & 12.8 & & 5832 & 6.0 & \\
\hline & Total & 7338 & 22.7 & & 7375 & 13.4 & & 7381 & 6.2 & \\
\hline
\end{tabular}


Citation: Miah RW, Apanga PA, Abdul-Haq Z (2016) Risk Factors for Undernutrition in Children under Five Years Old: Evidence from the 2011 Ghana Multiple Indicator Cluster Survey. J AIDS Clin Res 7: 585. doi:10.4172/2155-6113.1000585

Page 6 of 10

\begin{tabular}{|c|c|c|c|c|c|c|c|c|c|c|}
\hline \multirow[t]{3}{*}{ Fever in last 2 weeks } & Yes & 1404 & 24.1 & 0.186 & 1409 & 17.1 & 0.001 & 1407 & 8.2 & 0.001 \\
\hline & No & 5934 & 22.4 & & 5965 & 12.5 & & 5972 & 5.7 & \\
\hline & Total & 7338 & 22.7 & & 7374 & 13.4 & & 7379 & 6.2 & \\
\hline \multirow[t]{3}{*}{ Location } & Urban & 3193 & 18.1 & 0.001 & 3196 & 10.5 & 0.001 & 3191 & 5.7 & 0.090 \\
\hline & Rural & 4145 & 26.3 & & 4178 & 15.5 & & 4190 & 6.6 & \\
\hline & Total & 7338 & 22.7 & & 7374 & 13.3 & & 7381 & 6.2 & \\
\hline \multirow[t]{11}{*}{ Region } & Western & 713 & 22.6 & 0.001 & 718 & 14.3 & 0.001 & 722 & 7.6 & 0.001 \\
\hline & Central & 723 & 23.1 & & 727 & 13.5 & & 728 & 5.5 & \\
\hline & Greater Accra & 1110 & 13.7 & & 1110 & 8.3 & & 1119 & 3.1 & \\
\hline & Volta & 589 & 22.1 & & 590 & 10.8 & & 597 & 8.5 & \\
\hline & Eastern & 812 & 21.3 & & 816 & 10.5 & & 811 & 6.8 & \\
\hline & Asante & 1370 & 21.7 & & 1377 & 11.9 & & 1367 & 6.6 & \\
\hline & Brong Ahafo & 655 & 19.2 & & 660 & 11.8 & & 661 & 3.2 & \\
\hline & Northern & 834 & 37.4 & & 836 & 24.2 & & 840 & 8.1 & \\
\hline & Upper East & 318 & 31.4 & & 322 & 19.9 & & 319 & 7.2 & \\
\hline & Upper West & 215 & 23.3 & & 219 & 15.1 & & 215 & 9.3 & \\
\hline & Total & 7339 & 22.7 & & 7375 & 13.3 & & 7379 & 6.2 & \\
\hline \multirow{6}{*}{$\begin{array}{l}\text { Household wealth } \\
\text { quintiles }\end{array}$} & Poorest & 1670 & 33.2 & 0.001 & 1687 & 20.0 & 0.001 & 1694 & 7.6 & 0.001 \\
\hline & Second & 1522 & 26.7 & & 1532 & 14.8 & & 1532 & 14.8 & \\
\hline & Third & 1528 & 22.8 & & 1526 & 13.2 & & 1526 & 13.2 & \\
\hline & Fourth & 1364 & 15.8 & & 1372 & 10.3 & & 1372 & 10.3 & \\
\hline & Richest & 1255 & 11.6 & & 1258 & 6.3 & & 1258 & 6.3 & \\
\hline & Total & 7339 & 22.7 & & 7375 & 13.4 & & 7375 & 13.4 & \\
\hline & & \multicolumn{3}{|c|}{ Stunting } & \multicolumn{3}{|c|}{ Underweight } & \multicolumn{3}{|c|}{ Wasting } \\
\hline Variable & Label & No. & $\%$ & $p$ & No. & $\%$ & $p$ & No. & $\%$ & $p$ \\
\hline \multirow[t]{3}{*}{ Child has health insurance } & Yes & 3945 & 21.6 & 0.013 & 3969 & 11.4 & 0.001 & 3955 & 4.7 & 0.001 \\
\hline & No & 3394 & 24.1 & & 3406 & 15.6 & & 3425 & 8.0 & \\
\hline & Total & 7339 & 22.8 & & 7375 & 13.4 & & 7380 & 62 & \\
\hline \multirow[t]{8}{*}{ Mother's age } & $15-19$ & 226 & 23.5 & 0.001 & 230 & 16.5 & 0.035 & 226 & 9.3 & 0.046 \\
\hline & $20-24$ & 1026 & 25.0 & & 1033 & 14.9 & & 1031 & 7.3 & \\
\hline & $25-29$ & 1692 & 22.2 & & 1697 & 13.5 & & 1695 & 7.0 & \\
\hline & $30-34$ & 1775 & 19.8 & & 1787 & 11.9 & & 1782 & 5.3 & \\
\hline & $35-39$ & 1240 & 20.9 & & 1237 & 11.9 & & 1238 & 5.5 & \\
\hline & $40-44$ & 601 & 27.3 & & 605 & 15.9 & & 601 & 6.5 & \\
\hline & $45-49$ & 316 & 26.3 & & 318 & 11.9 & & 325 & 8.3 & \\
\hline & Total & 6876 & 22.4 & & 6907 & 13.2 & & 6898 & 6.4 & \\
\hline Father's age & $<25$ years & 162 & 26.5 & 0.001 & 162 & 18.5 & 0.001 & 162 & 7.4 & 0.371 \\
\hline & $25-29$ years & 764 & 24.3 & & 771 & 17.3 & & 764 & 7.5 & \\
\hline & $30-34$ years & 1277 & 21.5 & & 1282 & 11.1 & & 1273 & 5.6 & \\
\hline & $35-39$ years & 1329 & 17.3 & & 1327 & 10.2 & & 1335 & 6.2 & \\
\hline & $40-44 y$ ears & 1019 & 20.9 & & 1027 & 13.6 & & 1028 & 5.8 & \\
\hline & $45-49$ years & 696 & 23.6 & & 696 & 14.9 & & 694 & 8.1 & \\
\hline & $50-54$ years & 361 & 28.5 & & 367 & 12.8 & & 364 & 6.6 & \\
\hline & Total & 6005 & 22.3 & & 6032 & 13.3 & & 6021 & 64 & \\
\hline Mother's literacy & Cannot read at all & 4520 & 25.5 & 0.001 & 4538 & 15.0 & 0.001 & 4539 & 6.7 & 0.086 \\
\hline & Only parts of a sentence & 554 & 18.1 & & 560 & 9.3 & & 556 & 4.5 & \\
\hline & Whole sentences & 993 & 18.2 & & 1003 & 10.6 & & 995 & 5.7 & \\
\hline & Total & 6067 & 23.6 & & 6101 & 13.8 & & 6090 & 6.4 & \\
\hline Mother's education & None & 2869 & 27.0 & 0.001 & 2883 & 16.4 & 0.001 & 2885 & 7.7 & 0.001 \\
\hline & Primary & 1589 & 25.2 & & 1602 & 13.7 & & 1605 & 5.1 & \\
\hline & Middle/JSS & 2515 & 18.2 & & 2523 & 10.8 & & 2526 & 5.2 & \\
\hline & Secondary+ & 365 & 9.9 & & 365 & 5.8 & & 365 & 6.0 & \\
\hline & Total & 7338 & 22.7 & & 7373 & 13.3 & & 7381 & 6.2 & \\
\hline
\end{tabular}




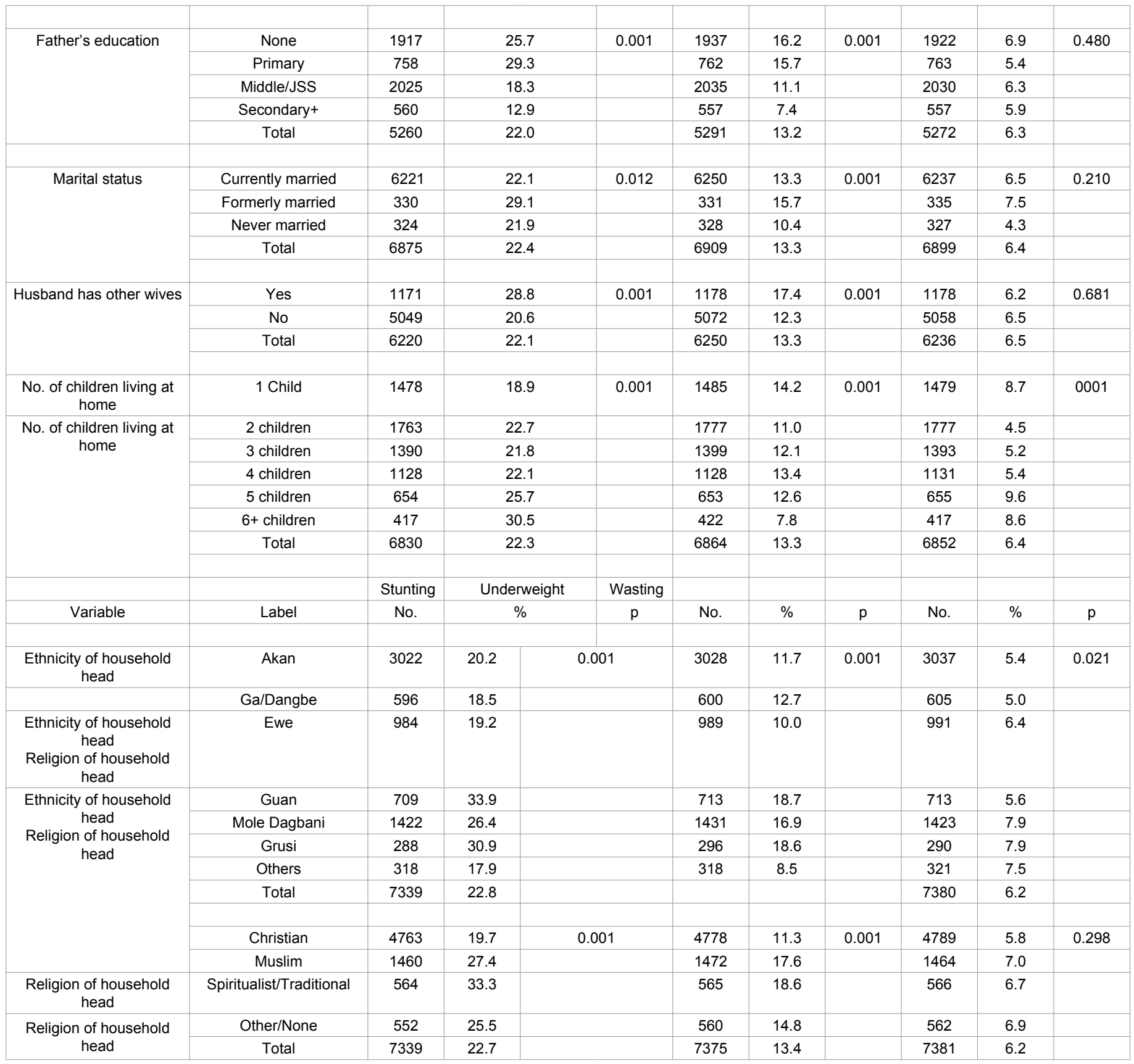

${ }^{a} A$ stunted child has a height-for-age Z-score that is below -2 SD based on the new WHO reference population

${ }^{\mathrm{b}} \mathrm{An}$ underweight child has a weight-for-age Z-score that is below -2 SD based on the new WHO reference population.

${ }^{c} \mathrm{~A}$ wasted child has a weight-for-height Z-score that is below $-2 \mathrm{SD}$ based on the new WHO reference population

P-value for bivariate ( $p$-value at 0.05 levels)

Table 2: Bivariate analysis showing associations between biological and non-biological variables and stunting, underweight and wasting.

than males and this might be accounting for our findings in this current study. The reported size of a child at birth predicted chronic undernutrition. Van de Poel et al. [25] observed same finding during the 2003 Ghana demographic and health survey. The intergenerational cycle of growth failure might be accounting for this outcome as there is an increased likelihood of mothers with low maternal height and weight coupled with inadequate nutrition before and during pregnancy giving birth to smaller babies [28]. Our findings show that very small or smaller than average babies were at a greater risk of stunting and underweight than larger babies. This may be attributed to smaller babies more likely to have slower catch up growth compared with larger babies [29].

The region of residence of children under five years old was a predictor of both chronic and acute undernutrition. Underweight prevalence was high in the Northern and Upper East regions which agree with the studies by Harding et al. [13] and Van De Poel et al. [25]. This trend may be due to the rainfall pattern and the prolong periods of drought in the Northern part of Ghana. Past prevalence of undernutrition in these regions might be a contributory factor [5], resulting into an intergenerational vicious cycle of undernutrition. 
The risk of stunting and wasting was lowest in the Brong-Ahafo which is unsurprising as it is the region regarded as the food basket of Ghana. Additionally, household wealth was a risk factor for chronic undernutrition which was in line with findings reported by Hong [30] and Van De Poel et al. [25] who found that children from better-off households had better nutritional outcomes than poorer households. Long term cumulative effect of food insecurity and poor accessibility to improved health, water and sanitation might be accounting for the higher prevalence of undernutrition in poorer households [31].

Children having health insurance was a risk factor for underweight. Having health insurance increases access to utilisation of health services in Ghana [32]. However, our findings on the contrary showed that having health insurance increased the risk of being underweight. This is probably because parents of 'sicker' children are more likely to get health insurance for their child. This study also reported currently breastfeeding, recent morbidity and number of children in a household as risk factors for acute undernutrition. Children who were currently breastfed were at higher risk of being underweight and wasted. In spite of the importance of breastfeeding, children are likely to become acutely undernourished if they are not fed on the appropriate complimentary foods [6] and this might be responsible for our observation. Fever is the leading cause of morbidity in children and accounts for $34 \%$ of under-five deaths [15]. A repeated episode of fever which is often due to malaria reduces the immune response of children increasing their vulnerability to infections [33]. Thus, children with fever are more likely to suffer from acute undernutrition than their peers without fever as reported in this study. Similarly, a recent history of diarrhoea was a risk factor for underweight. The prevalence of diarrhoea is common in developing countries like Ghana where water and sanitation facilities are inadequate and are associated with a decrease in weight $[34,35]$. Nearly a quarter of Ghanaian households do not have access to toilet facilities and portable water which leaves them with no choice than to defecate in the open [15], making children more vulnerable to diarrhoeal diseases and other infections.

In addition, having three or more children in a household increased the risk of undernutrition. This may be due to increased competition for household foods which may affect both the quality and quantity of food given at home. Adequate maternal attention and care may also decrease whilst overcrowding may increase as a result of an increase in number of children living in a household. These tend to make children more vulnerable to the spread of infections and morbidity and more likely to suffer from undernutrition [36].

We believe that our study is strong as findings are based on a national representative survey data that recruited a large sample size of 7,550 children under five years old using standardised data collection methods. It also included a wealth/asset index to capture economic or income status because it is difficult to obtain reliable and accurate data on income expenditure. However, our study was limited as it was conducted outside the food shortage season (March to June), hence this might have affected weight measurements of children. This study did not also analyse the dietary intakes as most of the information collected on the MICS was on micronutrient intake. Thus, no analysis on feeding practices in terms of frequency, amount and density of food consumed was conducted.

\section{Conclusion}

The findings of this study provide evidence of chronic and acute undernutrition still prevalent in children under five years old in Ghana. Independent risk factors for undernutrition were identified as sex, age, reported size at birth, breastfeeding status, number of children in a household, child having health insurance, fever, diarrhoea, household wealth, ethnicity and region of residence. In order to improve on the health and nutritional status of children in Ghana, a holistic and inter-sectorial collaboration and consultation between the

\begin{tabular}{|c|c|c|c|c|c|c|c|c|c|c|}
\hline \multirow[b]{3}{*}{ Variable } & \multirow[b]{3}{*}{ Label } & \multicolumn{3}{|c|}{ Stunting } & \multicolumn{3}{|c|}{ Underweight } & \multicolumn{3}{|c|}{ Wasting } \\
\hline & & \multirow[b]{2}{*}{ OR } & \multicolumn{2}{|c|}{$95 \% \mathrm{Cl}$} & \multirow[b]{2}{*}{ OR } & \multicolumn{2}{|c|}{$95 \% \mathrm{Cl}$} & \multirow[b]{2}{*}{ OR } & \multicolumn{2}{|c|}{$95 \% \mathrm{Cl}$} \\
\hline & & & Lower & Upper & & Lower & Upper & & Lower & Upper \\
\hline \multirow{6}{*}{ Age of child (months) } & $0-5^{\wedge}$ & 1.00 & & & 1.00 & & & 1.00 & & \\
\hline & $6-11$ & 1.35 & 0.98 & 1.87 & 2.33 & 1.68 & 3.22 & 1.10 & 0.80 & 1.50 \\
\hline & $12-24$ & 3.84 & 2.94 & 5.00 & 3.35 & 2.49 & 4.49 & 0.90 & 0.68 & 1.20 \\
\hline & $24-35$ & 6.12 & 4.29 & 8.72 & 4.51 & 2.55 & 7.99 & 0.76 & 0.51 & 1.13 \\
\hline & $36-47$ & 4.04 & 3.00 & 5.43 & 3.24 & 1.91 & 5.51 & 0.42 & 0.25 & 0.68 \\
\hline & $48-59$ & 3.43 & 2.54 & 4.62 & 3.60 & 2.12 & 6.13 & 0.50 & 0.30 & 0.82 \\
\hline & & \multicolumn{3}{|c|}{ Stunting } & \multicolumn{3}{|c|}{ Underweight } & \multicolumn{3}{|c|}{ Wasting } \\
\hline & & \multicolumn{3}{|c|}{$95 \%$ C.I } & \multicolumn{3}{|c|}{$95 \%$ C.I } & \multicolumn{3}{|c|}{$95 \%$ C.I } \\
\hline Variable & Label & OR & Lower & Upper & OR & Lower & Upper & OR & Lower & Upper \\
\hline \multirow{2}{*}{ Sex of child } & Male $^{\wedge}$ & 1.00 & & & 1.00 & & & 1.00 & & \\
\hline & Female & 0.74 & 0.64 & 0.87 & 0.71 & 0.60 & 0.84 & 0.62 & 0.51 & 0.75 \\
\hline \multirow{5}{*}{ Reported size of child at birth } & Very large $^{\wedge}$ & 1.00 & & & 1.00 & & & & & \\
\hline & $\begin{array}{l}\text { Larger than } \\
\text { average }\end{array}$ & 1.46 & 1.10 & 1.93 & 1.15 & 0.82 & 1.61 & & & \\
\hline & Average & 1.71 & 1.31 & 2.23 & 1.81 & 1.32 & 2.49 & & & \\
\hline & $\begin{array}{l}\text { Smaller than } \\
\text { average }\end{array}$ & 2.28 & 1.63 & 3.17 & 2.59 & 1.78 & 3.77 & & & \\
\hline & Very small & 2.17 & 1.38 & 3.42 & 3.06 & 1.89 & 4.95 & & & \\
\hline
\end{tabular}




\begin{tabular}{|c|c|c|c|c|c|c|c|c|c|c|}
\hline \multirow{2}{*}{ Currently breastfed } & Yes $^{\wedge}$ & & & & 1.00 & & & 1.00 & & \\
\hline & No & & & & 0.59 & 0.39 & 0.89 & 0.57 & 0.40 & 0.80 \\
\hline \multirow{2}{*}{ Diarrhoea in last 2 weeks } & Yes $^{\wedge}$ & & & & 1.00 & & & & & \\
\hline & No & & & & 0.73 & 0.59 & 0.90 & & & \\
\hline \multirow{2}{*}{ Fever in last 2 weeks } & Yes $^{\wedge}$ & & & & & & & 1.00 & & \\
\hline & No & & & & & & & 0.73 & 0.59 & 0.89 \\
\hline \multirow{6}{*}{ No. of children living at home } & 1 child $^{\wedge}$ & & & & & & & 1.00 & & \\
\hline & 2 children & & & & & & & 0.72 & 0.54 & 0.97 \\
\hline & 3 children & & & & & & & 0.79 & 0.59 & 1.05 \\
\hline & 4 children & & & & & & & 0.85 & 0.63 & 1.15 \\
\hline & 5 children & & & & & & & 1.25 & 0.92 & 1.70 \\
\hline & $6+$ children & & & & & & & 1.08 & 0.75 & 1.56 \\
\hline & & & & & & & & & & \\
\hline \multirow{10}{*}{ Region } & Western^ & 1.00 & & & 1.00 & & & 1.00 & & \\
\hline & Central & 0.83 & 0.57 & 1.22 & 1.16 & 0.73 & 1.84 & 0.80 & 0.50 & 1.30 \\
\hline & Greater Accra & 0.65 & 0.37 & 1.16 & 0.82 & 0.40 & 1.66 & 0.60 & 0.31 & 1.17 \\
\hline & Volta & 0.76 & 0.45 & 1.29 & 0.84 & 0.46 & 1.54 & 1.17 & 0.68 & 2.03 \\
\hline & Eastern & 1.13 & 0.69 & 1.85 & 1.24 & 0.68 & 2.24 & 0.95 & 0.53 & 1.72 \\
\hline & Asante & 1.07 & 0.69 & 1.65 & 1.44 & 0.84 & 2.45 & 0.92 & 0.53 & 1.61 \\
\hline & Brong Ahafo & 0.63 & 0.38 & 1.03 & 1.03 & 0.57 & 1.84 & 0.42 & 0.21 & 0.83 \\
\hline & Northern & 1.37 & 0.92 & 2.06 & 2.02 & 1.32 & 3.11 & 1.12 & 0.73 & 1.72 \\
\hline & Upper East & 1.05 & 0.67 & 1.65 & 1.65 & 1.02 & 2.66 & 1.09 & 0.68 & 1.73 \\
\hline & Upper West & 0.75 & 0.48 & 1.16 & 1.48 & 0.92 & 2.36 & 1.20 & 0.77 & 1.88 \\
\hline \multirow{5}{*}{ Household wealth quintile } & Poorest $^{\wedge}$ & 1.00 & & & 1.00 & & & & & \\
\hline & Second & 0.91 & 0.74 & 1.13 & 1.01 & 0.80 & 1.28 & & & \\
\hline & Third & 0.86 & 0.66 & 1.12 & 1.02 & 0.76 & 1.38 & & & \\
\hline & Fourth & 0.47 & 0.34 & 0.64 & 0.87 & 0.62 & 1.22 & & & \\
\hline & Richest & 0.42 & 0.28 & 0.63 & 0.40 & 0.23 & 0.70 & & & \\
\hline \multirow{2}{*}{ Child has health insurance } & $\mathrm{No}^{\wedge}$ & & & & 1.0 & & & & & \\
\hline & Yes & & & & 1.56 & 1.30 & 1.87 & & & \\
\hline & & & & & & & & & & \\
\hline \multirow{7}{*}{ Ethnicity of household head } & Akan^ & 1.00 & & & & & & & & \\
\hline & Ga/Dangbe & 0.79 & 0.48 & 1.32 & & & & & & \\
\hline & Ewe & 0.70 & 0.47 & 1.05 & & & & & & \\
\hline & Guan & 0.98 & 0.69 & 1.39 & & & & & & \\
\hline & Mole Dagbani & 0.99 & 0.72 & 1.37 & & & & & & \\
\hline & Grusi & 1.40 & 0.92 & 2.12 & & & & & & \\
\hline & Others & 0.62 & 0.40 & 0.98 & & & & & & \\
\hline Religion of household head & Christian^ $^{\wedge}$ & 1.00 & & & & & & & & \\
\hline \multirow{3}{*}{ Religion of household head } & Muslim & 1.42 & 1.14 & 1.77 & & & & & & \\
\hline & $\begin{array}{l}\text { Spiritualist/ } \\
\text { Traditionalist }\end{array}$ & 1.46 & 1.15 & 1.85 & & & & & & \\
\hline & Other/None & 1.12 & 0.82 & 1.54 & & & & & & \\
\hline
\end{tabular}

OR=Odd ratio, ${ }^{\wedge}$ Reference population

Table 3: Logistic regression analysis showing relative risk of being stunted, underweight and wasted.

Ministry of Health/Ghana Health Service with relevant stakeholders such as the District Assemblies, the Environmental and Sanitation Department, the National Health Insurance Authority, the Ministry of Education, Ministry of Food and Agriculture is needed to design and implement result oriented policies and intervention programmes to tackle undernutrition in Ghana. Policies and nutrition intervention programmes should be geared towards boosting household income, increasing access to food supplies, improving water and sanitation facilities both in rural and urban areas as well as access to healthcare by all. Further inter-disciplinary research is needed to understand how behavioural and resource allocation of some ethnicities and regions respectively have higher prevalence of undernutrition in Ghana.

\section{Authors' Contribution}

RWM and PAA conceived and designed the study and analyzed the data and wrote the first draft. ZA critically revised the draft for important intellectual content. All authors read and approved the final manuscript.

\section{Acknowledgement}

We are indebted to Dr. Penelope Nestel, Prof. Allan Jackson, Dr. Emma 
Parsons, Dr. Jacqueline Landman, and Dr. Steve Wootton who supported us during this study. We also thank the GSS for release of the MICS data and permitting us to use it.

\section{References}

1. The state of food insecurity in the world (2004) The Food and Agricultura Organization- Rome.

2. The state of the world's children: Child survival: UNICEF; 2007 (2008) United Nations Children's Fund.

3. Black RE, Victora CG, Walker SP, Bhutta ZA, Christian P, et al. (2013) Materna and child undernutrition and overweight in low-income and middle-income countries. Lancet 382: 427-451.

4. Improving Child Nutrition: the achievable imperative for global progress (2013) United Nations Children's Fund.

5. Van de Poel E, Hosseinpoor AR, Jehu-Appiah C, Vega J, Speybroeck N (2007) Malnutrition and the disproportional burden on the poor: the case of Ghana. Int J Equity Health 6: 21

6. Black RE, Allen LH, Bhutta ZA, Caulfield LE, de Onis M, et al. (2008) Maternal and child undernutrition: global and regional exposures and health consequences. Lancet 371: 243-260.

7. Brabin BJ, Coulter JBS (2003) Nutrition-associated disease. Manson's tropical diseases. Saunders, London.

8. Scrimshaw NS, SanGiovanni JP (1997) Synergism of nutrition, infection, and immunity: an overview. Am J Clin Nutr 66: 464S-477S.

9. Grantham-McGregor S, Cheung YB, Cueto S, Glewwe P, Richter L, et al (2007) Developmental potential in the first 5 years for children in developing countries. Lancet 369: 60-70.

10. Repositioning Nutrition as Central to Development: A Strategy for Large-Scale Action (2006) The World Bank.

11. Comprehensive food security and vulnerability analysis-Ghana: A focus on Northern Ghana (2012) World Food Programme.

12. Performance of the Agricultural Sector in Ghana: 2006-2012 (2012) Ministry of Food and Agriculture.

13. Harding K, Marquis GS, Colecraft EK, Lartey A, Sakyi-Dawson OA (2008) Comparison of child nutritional status in two agro-ecological zones of Ghana: Is location an important determinant? Faseb Journal 22.

14. Ghana Meteorological Agency (2015) GMET.

15. Ghana Statistical Service (2011) Multiple indicator cluster survey 2011 with an enhance malariamodule and biomarker.

16. Osumanu KI, Abdul-Rahim L, Songsore J, Braimah FR, Mulenga M (2010) Urban water and sanitation in Ghana: how local action is making a difference. Human settlements working paper Series Water and Sanitation 25.

17. Heidkamp RA, Ayoya MA, Teta IN, Stoltzfus RJ, Marhone JP (2015) Complementary feeding practices and child growth outcomes in Haiti: an analysis of data from Demographic and Health Surveys. Matern Child Nutr 11: 815-828.
18. Adom BG (2010) Nutrition policy and programs in Ghana: The limitations of a single sector approach. Health, Nutrition and Population Discussion Paper.

19. National Population and Housing Census (2010) Ghana Statistical Service.

20. WHO Global Database on Child Growth and Malnutrition (1997) World Health Organization Geneva, Switzerland.

21. Das S, Rahman RM (2011) Application of ordinal logistic regression analysis in determining risk factors of child malnutrition in Bangladesh. Nutr J 10: 124.

22. Kabubo-Mariara J, Ndenge GK, Mwabu DK (2009) Determinants of children's nutritional status in Kenya: Evidence from demographic and health surveys. Journal of African Economies 18: 363-387

23. Richard SA, Black RE, Gilman RH, Guerrant RL, Kang G, et al. (2012) Wasting is associated with stunting in early childhood. J Nutr 142: 1291-1296.

24. Babatunde RO, Qaim M (2010) Impact of off-farm income on food security and nutrition in Nigeria. Food policy 35: 303-311.

25. Van de Poel E, Hosseinpoor AR, Speybroeck N, Van Ourti T, Vega J (2008) Socioeconomic inequality in malnutrition in developing countries. Bulletin of the World Health Organization 86: 282-291.

26. Wamani H, Åstrøm AN, Peterson S, Tumwine JK, Tylleskär T (2007) Boys are more stunted than girls in sub-Saharan Africa: a meta-analysis of 16 demographic and health surveys. BMC Pediatr 7: 17.

27. Zere E, McIntyre D (2003) Inequities in under-five child malnutrition in South Africa. Int J Equity Health 2: 7.

28. Osrin D, de L Costello AM (2000) Maternal nutrition and fetal growth: practical issues in international health. Semin Neonatol 5: 209-219.

29. Brandt I, Sticker EJ, Gausche R, Lentze MJ (2012) Catch-Up Growth and Supine Length/Height in Very Low Birth Weight, Small for Gestational Age Preterm Infants. J Pediatr. 662-668.

30. Hong R (2007) Effect of economic inequality on chronic childhood undernutrition in Ghana. Public Health Nutr 10: 371-378.

31. Chronic undernutrition among children: an indicator of poverty (2015) Food and Agriculture Organization

32. Buor D (2003) Mothers' education and childhood mortality in Ghana. Health Policy 64: 297-309.

33. Caulfield LE, Richard SA, Black RE (2004) Undernutrition as an underlying cause of malaria morbidity and mortality in children less than five years old. Am J Trop Med Hyg 71: 55-63.

34. Keusch GTFO, Bhargava A, Boschi-Pinto C, Bhutta ZA, Gotuzzo E, et al. (2006) Diarrheal diseases. Disease Control Priorities in Developing Countries (2 $2^{\text {nd }}$ Edn.) Oxford University Press, Oxford 371-88.

35. Alam DS, Marks GC, Baqui AH, Yunus M, Fuchs GJ (2000) Association between clinical type of diarrhoea and growth of children under 5 years in rura Bangladesh. Int J Epidemiol 29: 916-921.

36. Dewey KG, Cohen RJ (2007) Does birth spacing affect maternal or child nutritional status? A systematic literature review. Matern Child Nutr 3: 151-173. 